\title{
Narrative review of the role of gastroenterologist in the diagnosis, treatment and palliation in gastric and gastroesophageal cancer
}

\author{
Liege I. Diaz ${ }^{1}$, Shruti Mony ${ }^{2}$, Jason Klapman ${ }^{1}$ \\ ${ }^{1}$ Department of Endoscopic Oncology, Moffitt Cancer Center, Tampa, FL, USA; ${ }^{2}$ Division of Digestive Diseases and Nutrition, University of South \\ Florida, Tampa, FL, USA \\ Contributions: (I) Conception and design: LI Diaz, J Klapman; (II) Administrative support: None; (III) Provision of study materials or patients: All \\ authors; (IV) Collection and assembly of data: LI Diaz, S Mony; (V) Data analysis and interpretation: LI Diaz, J Klapman; (VI) Manuscript writing: \\ All authors; (VII) Final approval of manuscript: All authors. \\ Correspondence to: Jason Klapman. Department of Endoscopic Oncology, Moffitt Cancer Center, Tampa, FL, USA. Email: Jason.Klapman@moffitt.org.
}

\begin{abstract}
Esophageal cancer (EC) and gastric cancer (GC) carry a high mortality rate. Unfortunately, a majority of patients are asymptomatic and at the time of diagnosis, the disease may invariably be in its advanced stages with limited curative options. Thus, it is imperative to recognize certain risk factors including gastroesophageal reflux disease (GERD), male gender, pre-existing Barrett's esophagus, smoking history, obesity, Helicobacter pylori infection, atrophic gastritis among others for both EC and GC, intervene on time with screening and surveillance modalities if indicated and optimize treatment plans. With advances in endoscopic techniques, early neoplastic lesions are increasingly managed by gastroenterologists, offering an alternative to surgery. The gold standard for diagnosis of EC and GC is high definition endoscopy with adequate targeted biopsies. Endoscopic ultrasound (EUS) is a key in the staging of early cancers dictating the pathway for treatment options. We also play a key role in palliation cases with the aim to reduce the symptoms like nausea, vomiting and even when possible, restore oral intake and improve nutrition in both advanced GC and EC. This review article discusses the risk factors, diagnostic and endoscopic treatment modalities of early EC and GC and palliation of advanced cancer where gastroenterologists play a key role.
\end{abstract}

Keywords: Esophageal; gastric; cancer; endoscopic ultrasound (EUS)

Submitted May 25, 2020. Accepted for publication Aug 12, 2020.

doi: $10.21037 / \mathrm{atm}-20-4143$

View this article at: http://dx.doi.org/10.21037/atm-20-4143

\section{Introduction}

Despite significant advances in diagnosis and treatment, esophageal cancer (EC) and gastric cancer (GC) remain largely fatal in most parts of the world.

EC is the 6th leading cause of death from cancer with a 5 -year survival around $15-25 \%$ (1). The prevalent histological type of EC worldwide is esophageal squamous cell carcinoma (SCC). However, in places like Australia, United Kingdom, United States and Western Europe, a predominance of adenocarcinoma subtype is noted. Esophagogastric junction (EGJ) and esophagus adenocarcinomas, especially Barrett's adenocarcinomas, have been on the rise in Western countries, whereas that of squamous cell cancer has been relatively stable in the same geographical location (2).

On the contrary, the incidence of GC in the United States continues to decline but remains the 5 th most commonly diagnosed cancer in the world (3). GC is more prevalent in underdeveloped countries with about half of all cases in Eastern Asia, particularly China (4). In Europe and the United States, the five-year survival rate is about 25 to 28 percent, increasing to about 63 percent if the cancer is diagnosed at an early stage. However, these survival rates are lower in underdeveloped countries where GC is typically detected at its advanced stage (4).

The gastroenterologist continues to play an important role in gastric and esophageal tumors with focus on early detection, proper surveillance of high-risk patients and 
accurate staging methods with the aim to prolong survival and improve the quality of life. Endoscopy and endoscopic ultrasound (EUS) have become an important tool in the diagnosis, staging, treatment, and palliation of patients with these cancers. We review the risk factors, diagnosis, staging, treatment and palliation of gastric and esophageal adenocarcinoma, with focus on early-stage disease and endoscopic therapy.

We present the following article in accordance with the Narrative Review reporting checklist (available at http:// dx.doi.org/10.21037/atm-20-4143).

\section{Definition and classification}

The universally accepted classification is the tumor, node, metastasis (TNM) staging system of the American Joint Committee on Cancer (AJCC)/Union for International Cancer Control (UICC) for EC and GC.

\section{EC}

The oldest and most widely used classification system is that by Siewert et al. (5) in 1987. This classification separates esophageal-gastric tumors based on the location of the epicenter of the tumor in relation to the location of the EGJ. Type I tumors are those with an epicenter 2-5 cm above the EGJ, they are also known as distal esophageal tumors. They usually arise from an area of Barrett's metaplasia in the lower esophagus and infiltrate the EGJ distally. Type II tumors are located within $2 \mathrm{~cm}$ (above or below) of the EGJ and type III are those $2-5 \mathrm{~cm}$ distal to the EGJ, also known as subcardial tumors (5).

According to the latest 8th edition revision of the AJCC staging classification, ECs are those EGJ tumors with epicenter less than $2 \mathrm{~cm}$ into the proximal stomach. In contrast, stomach cancers are those EGJ tumors found $2 \mathrm{~cm}$ or more into the proximal stomach as well as those cardia cancers not involving the EGJ, regardless of their location from the EGJ (6). This Classification guides surgical, medical and radiation oncology management.

\section{GC}

Based on the anatomic location, gastric adenocarcinomas are classified primarily as cardia and non-cardia. Gastric cardia cancers occur more adjacent to the EGJ and they share similar epidemiological qualities with esophageal adenocarcinomas. More commonly are non-cardia cancers appearing more distal in the stomach (7). GC can also be classified as diffuse (infiltrative) type or as intestinal type. One of the differences between them is that endoscopically, the intestinal type usually shows a gastric mass while the diffuse type (Linitis plastica) is more in line with a gastritis appearance and biopsies could be negative. Therefore, EUS becomes the procedure of choice as it can establish a malignant diagnosis by having the ability to perform fine needle aspiration (FNA) of the deeper gastric wall layers where the cancer may originate.

\section{Risk factors}

EC

Risk factors of esophageal adenocarcinoma cancer include chronic gastroesophageal reflux disease (GERD), male gender, pre-existing Barrett's esophagus, smoking history, high body mass index and certain drugs (8).

In men, the occurrence of esophageal adenocarcinoma is 8 times more common than those in women and 5 times more common in Caucasians than in African Americans in the United States (9). The odds ratio of developing adenocarcinoma in those with a BMI in the 25-30 rank is 1.52 when compared to those with normal BMI (9). Abdominal obesity which occurs more frequently in males, regardless of BMI rank, appears to be linked with a higher probability of acquiring esophageal adenocarcinoma but it is not associated with an increase of cardia adenocarcinoma $(9,10)$.

There is a positive correlation in the last 30 years between higher occurrences of Barrett's esophagus and adenocarcinomas during the same time frame. Out of those patients diagnosed with GERD, 6-14\% develop BE and $0.5-1 \%$ will develop adenocarcinoma (11). Finding of lowgrade dysplasia was connected with an occurrence rate for adenocarcinoma of 5.1 incidents per 1,000 person-years while patients with no dysplasia saw an incidence of 1.0 case per 1,000 person-years (12).

Data regarding the protective effect of Helicobacter pylori (H. pylori) on the development of esophageal adenocarcinoma is conflicting. Several studies have demonstrated that $H$. pylori is not more common and does not have a different distribution in patients with Barrett's esophagus than in controls (13-18). In contrast, H. pylori may be a significant factor for cardia inflammation and intestinal metaplasia, a precursor lesion for cardia adenocarcinoma (19). Cardiac adenocarcinoma may be 
difficult to distinguish from cancers arising in the distal esophagus, particularly when the disease is advanced.

\section{$G C$}

Risk factors for GC include male gender, cigarette smoking, atrophic gastritis, gastric intestinal metaplasia (GIM), H. pylori infection, partial gastrectomy and Ménétrier's disease (20). Several dietary factors, like a high salt, red meat, and smoked food consumption, as well as a low fruit and vegetables intake, and smoking have been incriminated as risk factors (21).

Gastric precancerous lesions such as atrophic gastritis and GIM (22), have a higher risk of GC (23) and their surveillance appears as a logical strategy to prevent advanced GC. Per AGA guidelines, surveillance should be reasonably considered in patients with GIM at higher risk for $\mathrm{GC}$ who have an increased value on potential but uncertain decrease in GC mortality, but add a low value on surveillance endoscopic risks. This includes incomplete and extensive GIM, family history of GC, racial/ethnic minorities and immigrants from high incidence regions. Data regarding recommendations on the ideal surveillance interval is insufficient. In patients with incidental GIM, repeated upper surveillance every 3-5 years should be considered with a cautious mucosal visualization and gastric biopsies of the antrum, body and all other lesions as long as there is a shared opinion favoring the surveillance (24).

H. pylori is a known cause of peptic ulcer disease (PUD) and is a carcinogen and should be tested and treated based on approved guidelines $(25,26)$. According to the ACG guidelines, patients should be tested for $H$. pylori infection if they have a history of endoscopy resection of early GC, a past history of PUD, active PUD or low grade gastric mucosa-associated lymphoid tissue (MALT) and those with a positive result should be offered eradication therapy (24). By eradicating $H$. pylori infection, the rate of metachronous GC after the endoscopic resection (ER) of gastric neoplasm was reduced (27-29).

\section{Screening}

EC

Upper esophagogastroduodenoscopy (EGD) has mostly substituted contrast radiology and it is the prefer examination. EGD permits to accurately identify the site of the tumor, as well as enabling biopsies for histological diagnosis.

There are no screening guidelines for EC. However, for individuals being evaluated for GERD, most society guidelines recommend performing EGD with biopsies for endoscopically visible BE (30-32). Patients should get screened for Barrett's Esophagus if many risk factors such as male sex, Caucasian race, age older than 50, obesity, chronic reflux symptoms, and a family history of EC are identified (30-32).

The gold standard for screening and surveillance of $\mathrm{BE}$ is with high-resolution white-light endoscopy with forceps biopsy (FB) sampling performed according to the Seattle protocol, which consists of taking biopsies of all quadrans every $1-2 \mathrm{~cm}$ through the suspected area. The aim of surveillance is detection of dysplasia. Most dysplasia and intra-mucosal cancers are focal and invisible to the endoscopist; for this reason, lack of good samples or inaccurate determination of landmarks can cause misdiagnosis of Barret's (33).

An extensive range of adjunctive methods to $\mathrm{FB}$ have been created to increase detection of $\mathrm{BE}$ and improve the finding of dysplastic areas. The American Society for Gastrointestinal Endoscopy has recently included widearea transepithelial sampling with computer-assisted three-dimensional analysis (WATS-3D) in its Standards of Practice Committee's guideline for the screening and surveillance of BE (34). It's a computer-assisted brushbiopsy method that utilizes an abrasive brush that takes a circumferential sweep of the esophagus. WATS-3D allows for the evaluation of more esophageal surface area as well as an assessment of deeper layer $(35,36)$. This sampling is followed by a computer assisted analysis that identifies potentially abnormal cells for pathologist review. Previous studies have shown that WATS-3D as an adjunct to both targeted and random FB increase the diagnostic yield and increases the detection of HGD/EAC in a high-risk population $(36,37)$.

\section{$G C$}

In Japan and Korea, where the frequency for GC is elevated in comparison to Western countries, screening for GC in the general population is common. In countries like the Unites States where incidence is low, general routine screening is not endorsed. However, there is an interest in considering screening and surveillance targeted populations based on risk factors like place of birth, race/ethnicity and other related factors for GC. 
While most GCs are considered sporadic, $5-10 \%$ have a genetic component and $3-5 \%$ are related with an inherited cancer predisposition syndrome (38-43). Among these syndromes are hereditary non-polyposis colorectal cancer, familial adenomatous polyposis, hereditary diffuse GC (CDH-1 mutations), Juvenile Polyposis Syndrome and Peutz Jeghers syndrome. Each condition has different screening and surveillance guidelines than the general population (41). The most relevant it's the CDH1 mutation carriers, who elect not to undergo prophylactic gastrectomy, we offered screening every 6-12 months by upper endoscopy with multiple random biopsies as recommend by National Comprehensive Cancer Network guidelines. When patients present symptoms, this usually includes dyspepsia, weight loss, dysphagia, vomiting, iron deficiency anemia and/or early satiety (20) and this should prompt examination starting with an EGD with biopsies of any abnormal mucosa with further imaging studies depending on findings.

\section{Diagnosis}

Diagnostic and surveillance endoscopies are performed for both EC and GC with the goal of determining the presence and location of neoplastic disease and to biopsy any suspicious lesions. The gold standard for diagnosis of EC and GC is high definition endoscopy with adequate targeted biopsies. The tremendous progress in the quality of endoscopic devices has allowed a marked improvement of our capacity to detect early neoplastic lesions.

\section{EC}

During endoscopy, attention should be paid to the site of the tumor in relation to the incisors and EGJ, length and extent of circumferential involvement, and the lumen diameter at the level of obstruction should be carefully recorded. In addition, the location, length and circumferential extent of Barrett's should be categorized according to the Prague criteria if present and mucosal nodules should be documented.

In addition to adequate inspection time, multiple endoscopic methods to improve the discovery of dysplasia with minimum biopsy sampling have been studied. Narrowband imaging (NBI) is valuable for finding esophageal squamous carcinoma but its use for EGJ adenocarcinoma detection is unknown. However, acetic acid splaying, chromoendoscopy with indigocarmine and NBI could be of use for finding such lesions $(44,45)$.

\section{$G C$}

Multiple (6-8) biopsies using standard size endoscopy forceps should be performed to provide adequately material for histologic interpretation, especially in the setting of an ulcerated lesion. This was shown in a prospective trial were 202 biopsy and cytology specimens were obtained from $\mathrm{EC}$ and GC which demonstrated that the diagnostic yield increased from $70 \%$ with one biopsy to greater than $98 \%$ when a total of seven biopsy specimens were collected (46).

\section{Pre-treatment staging}

Preoperative tumor staging is endorsed to all patients, especially those known to be surgical candidates because their disease extent will influence treatment planning.

A computed tomography scan often begins the staging by evaluating the existence of metastatic disease (i.e., to bone, lung, liver or adrenals), thus distinguishing M0 vs. M1 stages. However, positron emission tomography (PET) CT scanning may be more precise for the discovery of stage IV disease and may be used as an early staging evaluation (47).

\section{$E C$}

EUS can provide three-dimensional images of esophageal lesions and is the most sensitive test for locoregional staging of EC $(34,48-51)$. It is also more precise than PET scanning, magnetic resonance imaging (MRI), CT scan or transabdominal ultrasound for locoregional staging of EC, with an overall accuracy of EUS for $\mathrm{T}$ and $\mathrm{N}$ staging of 90 percent (52). The universally accepted staging system-the tumor, node, metastasis staging system of the American Joint Committee on Cancer and the Union for International Cancer Control for EC (2017, eighth edition) (53) is shown in Table 1.

The endosonography report should include the endoscopic findings of tumor location, features (e.g., circumferential extent, skip areas, presence/absence of Barrett's), anatomic landmarks [gastroesophageal junction (GEJ), diaphragmatic hiatus, squamocolumnar junction], as well as a description incorporating the T-stage including maximal wall thickness, $\mathrm{N}$-stage with specific features of identified lymph nodes (location, shape/size/border/ echogenicity) and signs of distant spread, such as lesions in nearby organs (M-category). Incomplete staging due 
Table 1 AJCC staging esophageal cancer -8 th edition cancer staging categories for cancer of the esophagus and GE junction

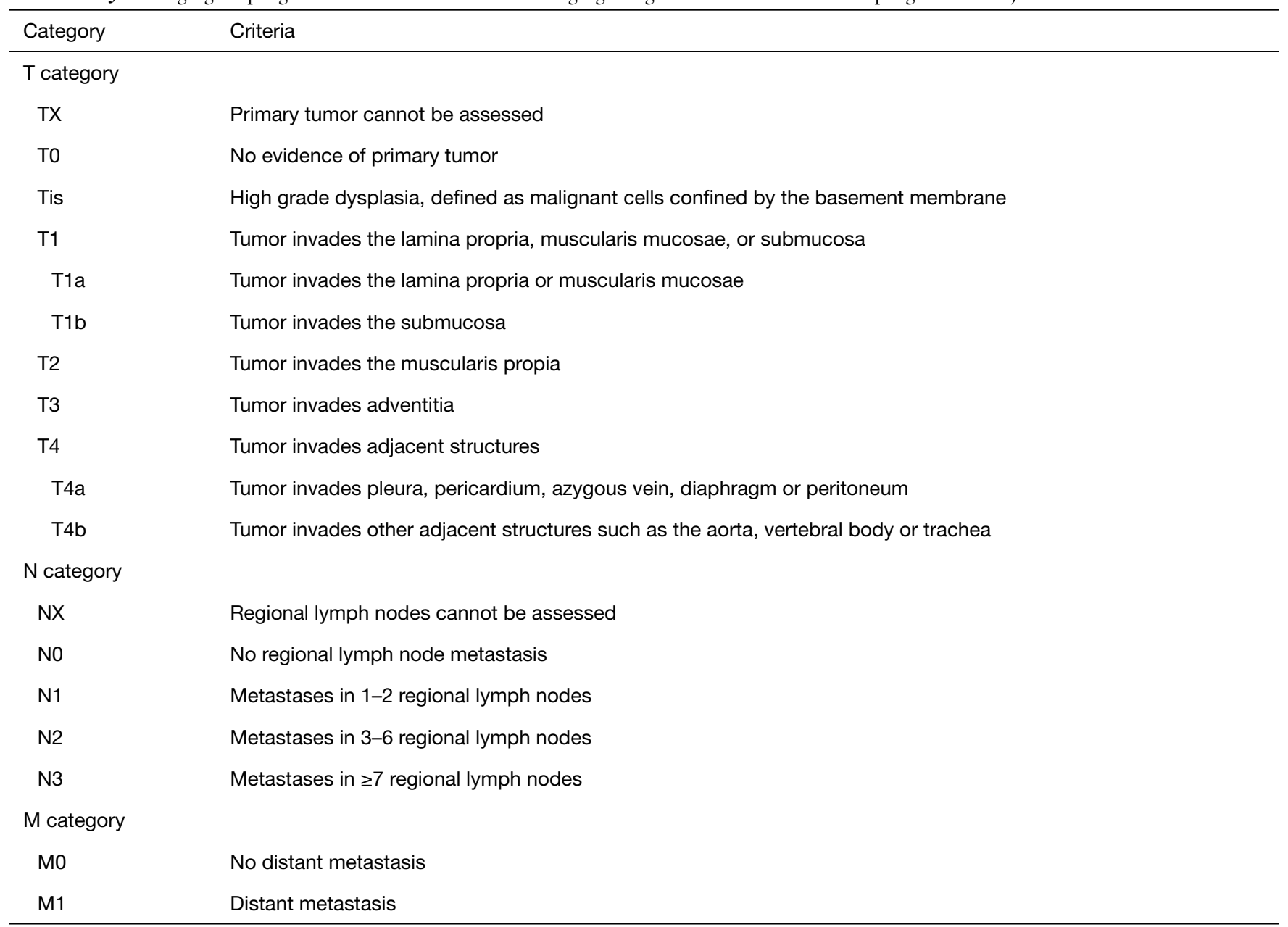

AJCC, American Joint Committee on Cancer.

to tumoral stenosis should be described $(48,52,53)$. The endosonographic appearance of the esophageal layers is shown in Figure 1.

Histologic analysis of the main tumor depth, lymphovascular invasion (LVI) and locoregional staging in superficial EC (T1 lesions, mostly $<2 \mathrm{~cm}$ ) could be achieved by using ER with EUS. Combining both procedures is a layer of preventive measure against staging errors by either histologic study or sonographic evaluation. The histology of endoscopically resected specimens could help with a more precise evaluation of superficial tumor invasion, sometimes difficult to visualize by standard radial EUS (7.5-12 MHz) $(54,55)$. ER and EUS can also have the benefit of study of the nodes with the possibility for FNA sampling. Additionally, EUS disregards invasive deeper cancer (T2 or deeper lesions) that makes ER needless and risky.
Data suggesting the use of EUS for cancers involving the EGJ is very restricted, and a broad use of ER has been advised (54). According to this study, EUS accuracy is diminished at the EGJ $v s$. other locations of the esophagus when analyzing resected specimens; with $29 \%$ overstaged and $23 \%$ under-staged by EUS. This effect is more pronounced with smaller, early EGJ cancers that resulted in over-staging for the most part.

For patients in the beginning of the disease process, EUS can influence the treatment as a more specific consideration may be given to the depth of esophageal invasion and celiac lymph node, which is believed to be an entrance for far metastatic spread (56). According to the latest data, prognosis of malignancy-involved lymph nodes is more important than regional anatomic location, which makes the indication of EUS-FNA stronger $(57,58)$. 


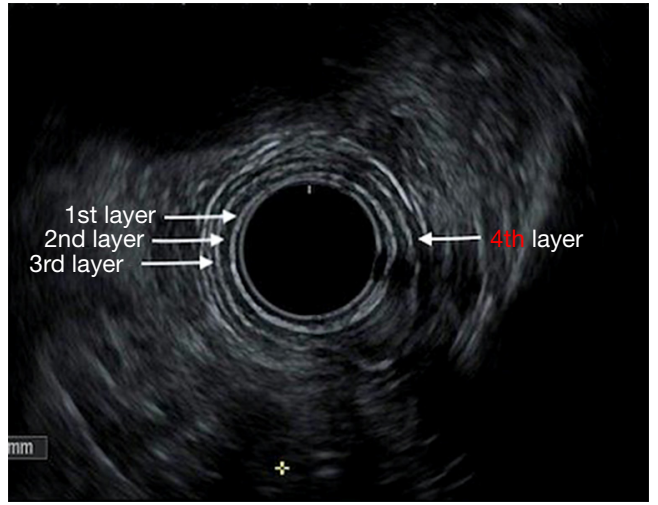

Figure 1 EUS depiction of esophageal layers. Layer 1: mucosa; layer 2: muscularis mucosa; layer 3 submucosal; layer 4: muscularis propia. EUS, endoscopic ultrasound.

The accuracy of this diagnosis is significantly increased by using FNA biopsy for further cytology analysis (49). FNA of questionable lymph nodes is recommended if the procedure can be done without going through a site of primary lesion or major blood vessels, and if the study will give additional information for future treatment strategies.

Tumors that obstruct the esophagus may be at higher risk of perforation while doing staging EUS exams. The perforation risk may be diminished by using mini-probes or wire guided EUS probes. In the past, dilation was done but now it is done less frequently as the risk of perforation does not outweigh the low benefit of complete staging and finding occult M1 disease not seen on other imaging modalities.

\section{GC staging}

The choice of staging modality is dependent on the clinical scenario and local expertise. Before any treatment, the use of EUS is key in the preliminary staging of CG (59). The endosonographic appearance of the gastric layers is shown in Figure 2. Cautious detail to the sonographic images provides evidence of depth tumor invasion (T-category), existence of suspicious or atypical lymph nodes with a high chance to harbor cancer ( $\mathrm{N}$-assessment), and signs of distant spread, such as lesions in nearby organs (M-category) or the presence of ascites. The most recent revision of the AJCC/UICC TNM staging classification (eighth edition, 2017) is shown in Table 2. This is primarily important for patients who are being considered for endoscopic submucosal dissection (ESD) or endoscopic

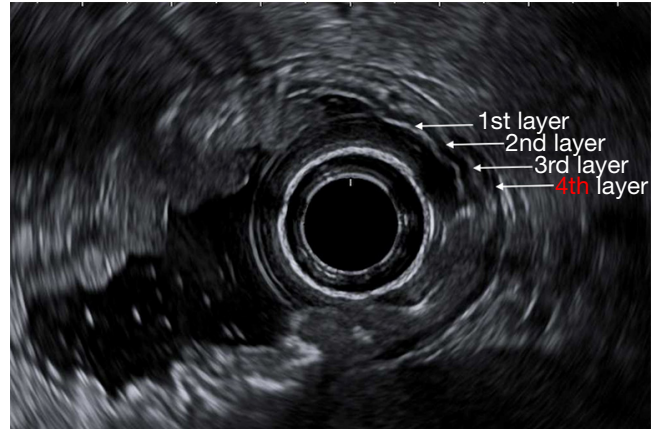

Figure 2 EUS depiction of gastric layers. Layer 1: mucosa; layer 2: muscularis mucosa; layer 3 submucosal; layer 4: muscularis propia. EUS, endoscopic ultrasound.

mucosal resection (EMR) (60). Focal nodules less or equal than $2 \mathrm{~cm}$ can be better studied by gathering a larger specimen with the use of EMR or ESD. This will provide more information regarding the degree of differentiation, existence of LVI, and the depth of infiltration, further giving a more precise T-staging as detailed below (61).

Early studies have concluded that the accuracy of EUS diagnostic for $\mathrm{T}$ staging varies from $43 \%$ to $88 \%$ (62-66). A recent meta-analysis and systematic review showed that the sensitivity GC N staging using EUS is quite high (82\%). But the specificity of EUS for the same $\mathrm{N}$ staging in GC was not as high (68\%) (67).

A dark or hypoechoic expansion with a steady loss of the layered pattern of the normal stomach wall is the location of the tumor correspond to T-categories. A hypoechoic expansion of the first 3 layers corresponds with an infiltration of the superficial, deep mucosa and submucosa, T1 disease. A dark expansion of layers 1-4 corresponds with invasion into the muscularis propria, $\mathrm{T} 2$ disease, and expansion further than the muscularis propria that results in an abnormal outer border that corresponds with penetration of the subserosa, T3 disease. Fingerlike projections of tumor, termed "pseudopodia" may be seen. Loss of the serosa which is recognized by a bright line, is staged as pT4a, and expansion of the lesion into nearby organs such as the spleen, pancreas and liver is staged $\mathrm{pT} 4 \mathrm{~b}$ disease (68).

EUS can quickly detect perigastric lymph nodes, and the detection of well-circumscribed, homogenous, hypoechoic, enlarged, rounded lesions around the stomach corresponds with the existence of malignant or inflammatory lymph nodes. The echoendoscope should go through the antrum and the whole peri-gastric area should be scanned 
Table 2 Stomach cancer TNM staging AJCC UICC 8th edition

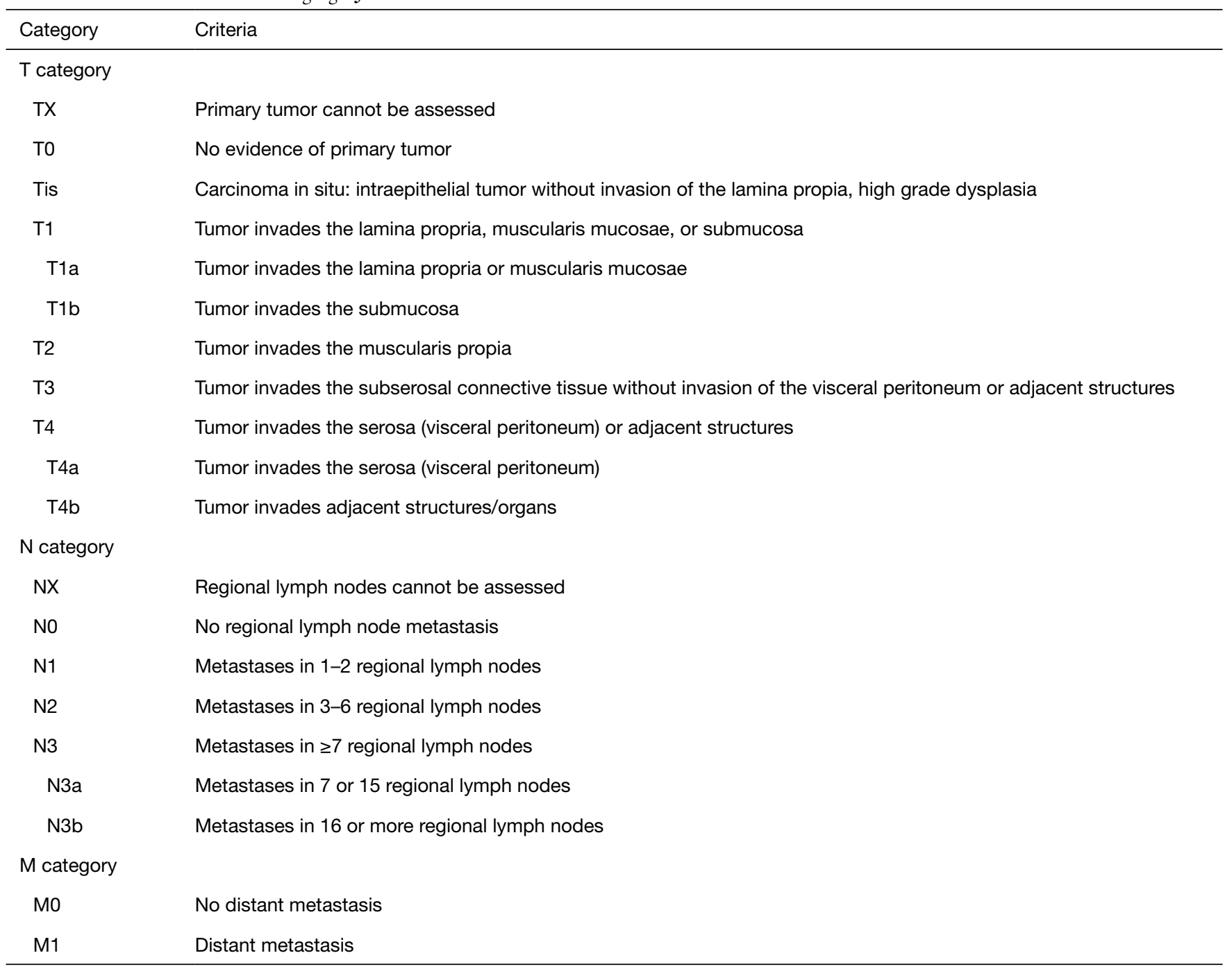

AJCC, American Joint Committee on Cancer; UICC, Union for International Cancer Control.

while retrieving it. FNA of questionable lymph nodes is recommended if the procedure can be done without going through a site of primary lesion or major blood vessels, and if the study will give additional information regarding treatment. Additionally, an effort should be made to detect the existence of ascites and FNA is recommended to rule out peritoneal spread of disease $(69,70)$.

Patients who appear to have locoregional disease after preoperative testing are potentially curable; all patients with a primary tumor $\mathrm{T} 2$ or higher or with a high suspicion of nodal involvement on pretreatment staging studies should be referred for multidisciplinary evaluation to identify the best treatment strategy (i.e., upfront surgery versus initial chemotherapy or chemoradiotherapy).

Gastric linitis plastica (GLP) is a diffuse, infiltrating carcinoma characterized by thickening and rigidity of the stomach wall (71). Because of the predominant submucosal or muscular infiltration, the positive rate for superficial biopsies in GLP patients is low and FNA can be performed to obtain a diagnosis. EUS is helpful for GLP surveillance and staging $(72,73)$. On EUS two findings can be seen. One is that the normal five-layer pattern is replaced by a homogenous, hypoechoic band. The second finding, the five-layer pattern appears intact, but the muscularis propria (fourth layer) is thickened and prominent, beneath a bright, hyperechoic submucosal layer. In both the gastric wall is 


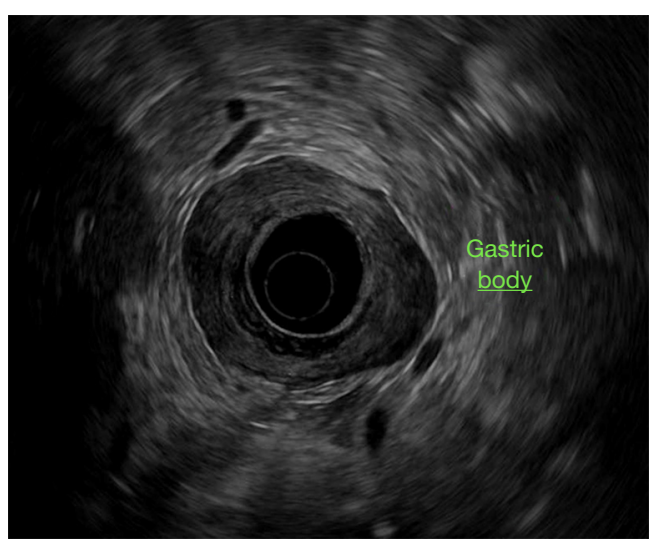

Figure 3 EUS findings in Linitis plastica. All five-layer pattern is obliterated and replaced by a homogenous band. EUS, endoscopic ultrasound.

thickened to $>4 \mathrm{~mm}(73)$ as seen in Figure 3.

\section{Treatment}

\section{EG endoscopy therapy}

TNM staging and tumor location will determine the optimal treatment strategy for adenocarcinomas of the GEJ. The depth of tumor invasion into the wall of the esophagus is an important factor in selecting treatment and must first be predicted based on visual findings at endoscopy and later confirmed by diagnostic ER if it is thought that superficial invasion is probable.

Early EC is defined as invasion depths consistent with Tis, T1a, and T1b staging. The American Society for Gastrointestinal Endoscopy guidelines recommend ER $(30,74)$ for both treating and staging suspected intramucosal adenocarcinoma, with the goal of eradication or complete removal of early disease. Endoscopic treatments include ablation, EMR or endoscopic mucosal dissection (ESD) $(30,74)$.

Tis or high-grade dysplasia: This stage has to be evaluated for the presence of nodularity, lateral spread and to rule out multifocal disease. The most use therapeutic approach is a combination of ER technique associated with ablative techniques to ablate the remaining dysplastic tissue. Nodular lesions showed be resected rather than ablated. The therapeutic efficacy can be up to $98 \%$. Potential complications include perforation, residual stenosis and bleeding (75). Other ablative methods include, cryoablation, photodynamic therapy (PDT) (76-80).
Mucosal adenocarcinomas (T1m1-m3/T1a): due to their estimated low risk of lymph node metastasis of approximately $1-2 \%$, LVI or poor differentiation grade, T1a tumors have the strongest indication to endoscopic treatment as definitive therapy (81).

Tis or T1a residual Barrett's esophagus should be ablative following mucosal resection. A more aggressive approach with EMR or ESD can also be performed at the initial intervention to resect completely an area of superficial tumor or nodular mucosa with a maximal dimension of $<2 \mathrm{~cm}(82,83)$.

The standard for mucosal cancer resection is band EMR, unless the target lesion is bulky or if there is suspicion of submucosal invasion, in which case ESD may be preferred to achieve en bloc resection. ESD has been accepted as a minimally invasive and curative treatment early EC (84). ESD helps with more accurate pathologic assessment that includes invasion depth, tumor margins and lymph vascular involvement. Reports on ESD efficacy for EGJ cancer have been reported but are still an area of controversy (85).

\section{T1b cancers}

These have an increased risk of nodal metastasis according to the $\mathrm{M} / \mathrm{SM}$ sub-classification system, exceeding $10 \%$, therefore definitive endoscopic therapy is generally not recommended $(81,82,86)$.

\section{GC endoscopy therapy}

Surgeons, gastroenterologist, pathologists, medical and radiation oncologist and dieticians should be part of the multidisciplinary treatment planning.

En bloc resection is considered for tumors with low probability of lymph node metastasis. A recent meta-analysis comparing EMR vs. ESD for early GC found that curative and complete resection is higher with ESD with lower risk of recurrence compared with patients who undergo EMR. However, ESD has increased risk of perforation and longer operational time (84). Furthermore, ESD requires greater skills and instrumentation to perform.

Per the Japanese guidelines (61), ER, as standard of treatment is indicated for non-ulcerative differentiatedtype adenocarcinoma T1a with a diameter $\leq 2 \mathrm{~cm}$. ESD is indicated as an investigational treatment in tumors clinically diagnosed as T1a and:

* Differentiated-type without ulcerative findings but $>2 \mathrm{~cm}$ in diameter, or;

- Ulcerative findings but $\leq 3 \mathrm{~cm}$ in diameter or; 
* Undifferentiated-type, without ulcerative findings and $\leq 2 \mathrm{~cm}$ in diameter.

If all of these conditions are fulfilled, the resection is considered endoscopic curability type A: en block resection, histologically differentiated type dominant, negative vertical and horizontal margins, any tumor size and no lymph vascular infiltration. Another ESD can be done for local mucosal recurrence after EMR/ESD. However, the validity of repeat ESD should be performed as part of investigational therapy given the paucity of this evidence (61).

Poorly differentiated GCs, evidence of LVI, deep submucosal invasion, positive deep or lateral margins, metastasis to lymph nodes after ESD or EMR should be considered to be incomplete. Gastrectomy with lymphadenectomy should be considered as additional therapy (87).

\section{Post-treatment endoscopic surveillance}

After completion of treatment, endoscopic surveillance should continue after ablative therapy or resection of early EC. Biopsies needs to be taken from the neo-squamous mucosa even if there are no mucosal abnormalities as dysplasia can present beneath the squamous mucosa. We should also look for the presence of BE and fourquadrant biopsies (Seattle protocol biopsy) should be taken to detect recurrent or residual dysplasia. Cryotherapy or RFA should be considered for the residual or recurrent dysplasia. Non-dysplastic BE does not need to be ablated $(53,81)$. For EC and GC, biopsies should be taken if any mucosal abnormalities or strictures are visualized to rule out neoplastic recurrence $(53,56)$.

Surveillance endoscopy every 3 months for one year and then annually, is recommended post treatment of Tis or T1a EC (88).

For GC, surveillance recommendations vary according to the depth of invasion and treatment modality and includes history and physical exam, complete blood count and chemistry profile as clinically indicated. For patients who had partial or subtotal gastrectomy, surveillance may include EGD, CT chest/abdomen/pelvis with oral and IV contrast and FDG-PET/CT for suspicious lesions seen on CT scan. The exact intervals and surveillance strategy are tailored to the stage at diagnosis and treatment plan in a multidisciplinary setting as suggested by National Comprehensive Cancer Network.

EUS post chemotherapy or radiation therapy has a reduced ability to accurately determine the stage of the disease post-treatment as it was shown in Ryun Park et al. study where forty patients with locally advanced GC underwent preoperative EUS and computed tomography (CT) after neoadjuvant chemotherapy. The accuracy of EUS and CT was found to be $47 \%$ and $57 \%$, respectively for $\mathrm{T}$ classification and $39 \%$ and $37 \%$, respectively for $\mathrm{N}$ classification $(50,89,90)$. After chemotherapy or radiation therapy, biopsies may not accurately diagnose the presence of residual disease neither. EUS should only be done in specific cases after neoadjuvant therapy when FNA of lymph node would change management

\section{Palliation}

\section{Endoscopic lumen restoration}

The goals of palliation therapy for patients with esophageal or gastric obstruction are to reduce the symptoms like nausea, vomiting and even when possible, restore oral intake and improve nutrition. Endoscopy options include placement of esophageal stent for EGJ/gastric cardia obstruction (GOO), relief of gastric outlet obstruction with enteral stent, percutaneous endoscopic gastrostomy or EUS-guided gastroenterostomy $(91,92)$.

Self-expandable metal stents (SEMS) are used increasingly as the primary palliation in advanced EC, specifically for dysphagia, intractable vomiting from underlying malignant strictures/fistula. It achieves rapid palliation, is safer and more cost-effective than the plastic esophageal prostheses used previously (93). However, stent ingrowth and overgrowth can be a problem, warranting repeat procedures (94).

For GOO, a large multicenter trial demonstrated high shortterm efficacy of palliative endoscopic stent placement (95). A Dutch multicenter randomized trial and a systematic review of randomized controlled trials demonstrated faster initial symptom relief in patients with stent placement compared with surgical gastrojejunostomy, but long-term relief was better after gastrojejunostomy. In addition, more major complications, recurrent symptoms, and need for reintervention occurred in the stent group $(91,96)$.

EUS-guided gastrojejunostomy using lumen-apposing metal stents has also been evaluated $(92,97)$. While efficacy was noted to be similar to surgical gastrojejunostomy, there are insufficient data to support this as an alternative to established procedures such as surgical gastrojejunostomy or duodenal stenting.

When obstruction cannot be alleviated, venting 
gastrostomy tube can be placed to reduce the obstructive symptoms (98). If tumor location permits, endoscopic, percutaneous or surgical gastrostomy tube placement can be done. The decision regarding whether to select gastrojejunostomy $v$ s. endoscopic stenting should depend on the life expectancy, condition and performance status of patients.

\section{Endoscopic therapy for bleeding}

The treatment of EC and GC may differ depending on the tumor characteristics. The data is limited however if bleeding appears to be primarily from tumor surface, then available therapeutic options include mechanical therapy, ablative therapy (cryotherapy, argon plasma coagulation, hemospray), injection therapy or a mixed of methods. When endoscopy methods are not helpful, angiography embolization could be useful in this situation $(89,99)$.

\section{Other palliative therapies}

External Beam radiation, PDT and brachytherapy may be considered in conjunction with endoscopic treatment or chemotherapy for control of bleeding or obstruction.

\section{Conclusions}

As endoscopic technologies and techniques evolve, the role of the gastroenterologist has shifted from being purely a diagnostician to now becoming an integral part of the multidisciplinary management of EGJ and GC patients. EUS provides accurate staging and guides management while ER for early lesions may be curative and obviate the need for more high-risk and invasive procedures and treatments. As we continue to work with the oncologic surgeons, medical and radiation oncologists, patients will continue to benefit from personalized treatments which will hopefully translate into better outcomes and long-term survival which is the ultimate goal.

\section{Acknowledgments}

Funding: None.

\section{Footnote}

Provenance and Peer Review: This article was commissioned by the Guest Editor (Dr. Khaldoun Almhanna) for the series "Gastroesophageal Cancer 2020" published in Annals of Translational Medicine. The article was sent for external peer review organized by the Guest Editor and the editorial office.

Reporting Checklist: The authors have completed the Narrative Review reporting checklist. Available at http:// dx.doi.org/10.21037/atm-20-4143

Conflicts of Interest: All authors have completed the ICMJE uniform disclosure form (available at http://dx.doi. org/10.21037/atm-20-4143). The series "Gastroesophageal Cancer 2020" was commissioned by the editorial office without any funding or sponsorship. The authors have no other conflicts of interest to declare.

Ethical Statement: The authors are accountable for all aspects of the work in ensuring that questions related to the accuracy or integrity of any part of the work are appropriately investigated and resolved.

Open Access Statement: This is an Open Access article distributed in accordance with the Creative Commons Attribution-NonCommercial-NoDerivs 4.0 International License (CC BY-NC-ND 4.0), which permits the noncommercial replication and distribution of the article with the strict proviso that no changes or edits are made and the original work is properly cited (including links to both the formal publication through the relevant DOI and the license). See: https://creativecommons.org/licenses/by-nc-nd/4.0/.

\section{References}

1. Pennathur A, Gibson MK, Jobe BA, et al. Oesophageal carcinoma. Lancet 2013;381:400-12.

2. Hatta W, Tong D, Lee YY, et al. Different time trend and management of esophagogastric junction adenocarcinoma in three Asian countries. Dig Endosc 2017;29 Suppl 2:18-25.

3. Bray F, Ferlay J, Soerjomataram I, et al. Global cancer statistics 2018: GLOBOCAN estimates of incidence and mortality worldwide for 36 cancers in 185 countries. CA Cancer J Clin 2018;68:394-424.

4. De Angelis R, Sant M, Coleman MP, et al. Cancer survival in Europe 1999-2007 by country and age: results of EUROCARE--5-a population-based study. Lancet Oncol 2014;15:23-34.

5. Siewert R, Lepsien G, Peiper HJ. [Carcinoma of the 
esophagus and cardia]. Internist (Berl) 1977;18:451-62.

6. Chevallay M, Bollschweiler E, Chandramohan SM, et al. Cancer of the gastroesophageal junction: a diagnosis, classification, and management review. Ann N Y Acad Sci 2018;1434:132-8.

7. Mukaisho K, Nakayama T, Hagiwara T, et al. Two distinct etiologies of gastric cardia adenocarcinoma: interactions among pH, Helicobacter pylori, and bile acids. Front Microbiol 2015;6:412.

8. Vial M, Grande L, Pera M. Epidemiology of adenocarcinoma of the esophagus, gastric cardia, and upper gastric third. Recent Results Cancer Res 2010;182:1-17.

9. Renehan AG, Tyson M, Egger M, et al. Body-mass index and incidence of cancer: a systematic review and metaanalysis of prospective observational studies. Lancet 2008;371:569-78.

10. Kubo A, Corley DA. Body mass index and adenocarcinomas of the esophagus or gastric cardia: a systematic review and meta-analysis. Cancer Epidemiol Biomarkers Prev 2006;15:872-8.

11. Wheeler JB, Reed CE. Epidemiology of esophageal cancer. Surg Clin North Am 2012;92:1077-87.

12. Hvid-Jensen F, Pedersen L, Drewes AM, et al. Incidence of adenocarcinoma among patients with Barrett's esophagus. N Engl J Med 2011;365:1375-83.

13. Corley DA, Kubo A, Levin TR, et al. Helicobacter pylori infection and the risk of Barrett's oesophagus: a community-based study. Gut 2008;57:727-33.

14. Fassan M, Rugge M, Parente P, et al. The role of Helicobacter pylori in the spectrum of Barrett's carcinogenesis. Cancer Prev Res (Phila) 2009;2:94.

15. Henihan RD, Stuart RC, Nolan N, et al. Barrett's esophagus and the presence of Helicobacter pylori. Am J Gastroenterol 1998;93:542-6.

16. Peng S, Cui Y, Xiao YL, et al. Prevalence of erosive esophagitis and Barrett's esophagus in the adult Chinese population. Endoscopy 2009;41:1011-7.

17. Sonnenberg A, Lash RH, Genta RM. A national study of Helicobactor pylori infection in gastric biopsy specimens. Gastroenterology 2010;139:1894-901 e2; quiz e12.

18. Wu AH, Crabtree JE, Bernstein L, et al. Role of Helicobacter pylori CagA+ strains and risk of adenocarcinoma of the stomach and esophagus. Int J Cancer 2003;103:815-21.

19. Goldblum JR, Vicari JJ, Falk GW, et al. Inflammation and intestinal metaplasia of the gastric cardia: the role of gastroesophageal reflux and H. pylori infection. Gastroenterology 1998;114:633-9.
20. Waddell T, Verheij M, Allum W, et al. Gastric cancer: ESMO-ESSO-ESTRO clinical practice guidelines for diagnosis, treatment and follow-up. Eur J Surg Oncol 2014;40:584-91.

21. Venneman K, Huybrechts I, Gunter MJ, et al. The epidemiology of Helicobacter pylori infection in Europe and the impact of lifestyle on its natural evolution toward stomach cancer after infection: A systematic review. Helicobacter 2018;23:e12483.

22. Nagami Y, Machida H, Shiba M, et al. Clinical Efficacy of Endoscopic Submucosal Dissection for Adenocarcinomas of the Esophagogastric Junction. Endosc Int Open 2014;2:E15-20.

23. de Vries AC, van Grieken NC, Looman CW, et al. Gastric cancer risk in patients with premalignant gastric lesions: a nationwide cohort study in the Netherlands. Gastroenterology 2008;134:945-52.

24. Gupta S, Li D, El Serag HB, et al. AGA Clinical Practice Guidelines on Management of Gastric Intestinal Metaplasia. Gastroenterology 2020;158:693-702.

25. Eusebi LH, Zagari RM, Bazzoli F. Epidemiology of Helicobacter pylori infection. Helicobacter 2014;19 Suppl $1: 1-5$.

26. Peleteiro B, Bastos A, Ferro A, et al. Prevalence of Helicobacter pylori infection worldwide: a systematic review of studies with national coverage. Dig Dis Sci 2014;59:1698-709.

27. Bang CS, Baik GH, Shin IS, et al. Helicobacter pylori Eradication for Prevention of Metachronous Recurrence after Endoscopic Resection of Early Gastric Cancer. J Korean Med Sci 2015;30:749-56.

28. Jung DH, Kim JH, Chung HS, et al. Helicobacter pylori Eradication on the Prevention of Metachronous Lesions after Endoscopic Resection of Gastric Neoplasm: A MetaAnalysis. PLoS One 2015;10:e0124725.

29. Yoon SB, Park JM, Lim CH, et al. Effect of Helicobacter pylori eradication on metachronous gastric cancer after endoscopic resection of gastric tumors: a meta-analysis. Helicobacter 2014;19:243-8.

30. ASGE Standards of Practice Committee, Evans JA, Early DS, et al. The role of endoscopy in Barrett's esophagus and other premalignant conditions of the esophagus. Gastrointest Endosc 2012;76:1087-94.

31. di Pietro M, Fitzgerald RC, group BSGBsgw. Revised British Society of Gastroenterology recommendation on the diagnosis and management of Barrett's oesophagus with low-grade dysplasia. Gut 2018;67:392-3.

32. Shaheen NJ, Falk GW, Iyer PG, et al. ACG Clinical 
Guideline: Diagnosis and Management of Barrett's Esophagus. Am J Gastroenterol 2016;111:30-50; quiz 1.

33. Wang KK, Sampliner RE, Practice Parameters Committee of the American College of G. Updated guidelines 2008 for the diagnosis, surveillance and therapy of Barrett's esophagus. Am J Gastroenterol 2008;103:788-97.

34. ASGE Standards of Practice Committee, Qumseya $\mathrm{B}$, Sultan S, et al. ASGE guideline on screening and surveillance of Barrett's esophagus. Gastrointest Endosc 2019;90:335-59.e2.

35. Anandasabapathy S, Sontag S, Graham DY, et al. Computer-assisted brush-biopsy analysis for the detection of dysplasia in a high-risk Barrett's esophagus surveillance population. Dig Dis Sci 2011;56:761-6.

36. Gross SA, Kingsbery J, Jang J, et al. Evaluation of Dysplasia in Barrett Esophagus. Gastroenterol Hepatol (N Y) 2018;14:233-9.

37. Vennalaganti PR, Kaul V, Wang KK, et al. Increased detection of Barrett's esophagus-associated neoplasia using wide-area trans-epithelial sampling: a multicenter, prospective, randomized trial. Gastrointest Endosc 2018;87:348-55.

38. Hampel H, Bennett RL, Buchanan A, et al. A practice guideline from the American College of Medical Genetics and Genomics and the National Society of Genetic Counselors: referral indications for cancer predisposition assessment. Genet Med 2015;17:70-87.

39. Kluijt I, Sijmons RH, Hoogerbrugge N, et al. Familial gastric cancer: guidelines for diagnosis, treatment and periodic surveillance. Fam Cancer 2012;11:363-9.

40. Oliveira C, Pinheiro H, Figueiredo J, et al. Familial gastric cancer: genetic susceptibility, pathology, and implications for management. Lancet Oncol 2015;16:e60-70.

41. Petrovchich I, Ford JM. Genetic predisposition to gastric cancer. Semin Oncol 2016;43:554-9.

42. Syngal S, Brand RE, Church JM, et al. ACG clinical guideline: Genetic testing and management of hereditary gastrointestinal cancer syndromes. Am J Gastroenterol 2015;110:223-62; quiz 263.

43. van der Post RS, Vogelaar IP, Carneiro F, et al. Hereditary diffuse gastric cancer: updated clinical guidelines with an emphasis on germline CDH1 mutation carriers. J Med Genet 2015;52:361-74.

44. di Pietro M, Canto MI, Fitzgerald RC. Endoscopic Management of Early Adenocarcinoma and Squamous Cell Carcinoma of the Esophagus: Screening, Diagnosis, and Therapy. Gastroenterology 2018;154:421-36.

45. Mannath J, Ragunath K. Role of endoscopy in early oesophageal cancer. Nat Rev Gastroenterol Hepatol 2016;13:720-30.

46. Graham DY, Schwartz JT, Cain GD, et al. Prospective evaluation of biopsy number in the diagnosis of esophageal and gastric carcinoma. Gastroenterology 1982;82:228-31.

47. Rice TW. Clinical staging of esophageal carcinoma. CT, EUS, and PET. Chest Surg Clin N Am 2000;10:471-85.

48. DaVee T, Ajani JA, Lee JH. Is endoscopic ultrasound examination necessary in the management of esophageal cancer? World J Gastroenterol 2017;23:751-62.

49. Keswani RN, Early DS, Edmundowicz SA, et al. Routine positron emission tomography does not alter nodal staging in patients undergoing EUS-guided FNA for esophageal cancer. Gastrointest Endosc 2009;69:1210-7.

50. Lightdale CJ, Kulkarni KG. Role of endoscopic ultrasonography in the staging and follow-up of esophageal cancer. J Clin Oncol 2005;23:4483-9.

51. van Vliet EP, Heijenbrok-Kal MH, Hunink MG, et al. Staging investigations for oesophageal cancer: a metaanalysis. Br J Cancer 2008;98:547-57.

52. Lee WC, Lee TH, Jang JY, et al. Staging accuracy of endoscopic ultrasound performed by nonexpert endosonographers in patients with resectable esophageal squamous cell carcinoma: is it possible? Dis Esophagus 2015;28:574-8.

53. Rice TW, Patil DT, Blackstone EH. 8th edition AJCC/UICC staging of cancers of the esophagus and esophagogastric junction: application to clinical practice. Ann Cardiothorac Surg 2017;6:119-30.

54. Dhupar R, Rice RD, Correa AM, et al. Endoscopic Ultrasound Estimates for Tumor Depth at the Gastroesophageal Junction Are Inaccurate: Implications for the Liberal Use of Endoscopic Resection. Ann Thorac Surg 2015;100:1812-6.

55. Young PE, Gentry AB, Acosta RD, et al. Endoscopic ultrasound does not accurately stage early adenocarcinoma or high-grade dysplasia of the esophagus. Clin Gastroenterol Hepatol 2010;8:1037-41.

56. Qumseya BJ, Brown J, Abraham M, et al. Diagnostic performance of EUS in predicting advanced cancer among patients with Barrett's esophagus and high-grade dysplasia/ early adenocarcinoma: systematic review and metaanalysis. Gastrointest Endosc 2015;81:865-74.e2.

57. Mariette C, Piessen G, Briez N, et al. The number of metastatic lymph nodes and the ratio between metastatic and examined lymph nodes are independent prognostic factors in esophageal cancer regardless of neoadjuvant chemoradiation or lymphadenectomy extent. Ann Surg 
2008;247:365-71.

58. Rizk N, Venkatraman E, Park B, et al. The prognostic importance of the number of involved lymph nodes in esophageal cancer: implications for revisions of the American Joint Committee on Cancer staging system. J Thorac Cardiovasc Surg 2006;132:1374-81.

59. Botet JF, Lightdale CJ, Zauber AG, et al. Preoperative staging of esophageal cancer: comparison of endoscopic US and dynamic CT. Radiology 1991;181:419-25.

60. Okada K, Fujisaki J, Kasuga A, et al. Endoscopic ultrasonography is valuable for identifying early gastric cancers meeting expanded-indication criteria for endoscopic submucosal dissection. Surg Endosc 2011;25:841-8.

61. Japanese Gastric Cancer A. Japanese gastric cancer treatment guidelines 2018 (5th edition). Gastric Cancer 2020. [Epub ahead of print].

62. Cho JW. The role of endoscopic ultrasonography in $T$ staging: early gastric cancer and esophageal cancer. Clin Endosc 2013;46:239-42.

63. Han C, Lin R, Shi H, et al. The role of endoscopic ultrasound on the preoperative $T$ staging of gastric cancer: A retrospective study. Medicine (Baltimore) 2016;95:e4580.

64. Hwang SW, Lee DH, Lee SH, et al. Preoperative staging of gastric cancer by endoscopic ultrasonography and multidetector-row computed tomography. J Gastroenterol Hepatol 2010;25:512-8.

65. Meyer L, Meyer F, Schmidt U, et al. Endoscopic ultrasonography (EUS) in preoperative staging of gastric cancer--demand and reality. Pol Przegl Chir 2012;84:152-7.

66. Yu T, Wang X, Zhao Z, et al. Prediction of T stage in gastric carcinoma by enhanced CT and oral contrastenhanced ultrasonography. World J Surg Oncol 2015;13:184.

67. Chen J, Zhou C, He M, et al. A Meta-Analysis And Systematic Review Of Accuracy Of Endoscopic Ultrasound For N Staging Of Gastric Cancers. Cancer Manag Res 2019;11:8755-64.

68. Amin MB, Greene FL, Edge SB, et al. The Eighth Edition AJCC Cancer Staging Manual: Continuing to build a bridge from a population-based to a more "personalized" approach to cancer staging. CA Cancer J Clin 2017;67:93-9.

69. de Graaf GW, Ayantunde AA, Parsons SL, et al. The role of staging laparoscopy in oesophagogastric cancers. Eur J Surg Oncol 2007;33:988-92.

70. Nath J, Moorthy K, Taniere P, et al. Peritoneal lavage cytology in patients with oesophagogastric adenocarcinoma. Br J Surg 2008;95:721-6.

71. Zhou XX, Pan HH, Usman A, et al. Endoscopic ultrasoundguided deep and large biopsy for diagnosis of gastric infiltrating tumors with negative malignant endoscopy biopsies. World J Gastroenterol 2015;21:3607-13.

72. Hassan H, Vilmann P, Sharma V. Impact of EUS-guided FNA on management of gastric carcinoma. Gastrointest Endosc 2010;71:500-4.

73. Shan GD, Xu GQ, Li YM. Endoscopic ultrasonographic features of gastric linitis plastica in fifty-five Chinese patients. J Zhejiang Univ Sci B 2013;14:844-8.

74. Moss A, Bourke MJ, Hourigan LF, et al. Endoscopic resection for Barrett's high-grade dysplasia and early esophageal adenocarcinoma: an essential staging procedure with long-term therapeutic benefit. Am J Gastroenterol 2010;105:1276-83.

75. Domper Arnal MJ, Ferrandez Arenas A, Lanas Arbeloa A. Esophageal cancer: Risk factors, screening and endoscopic treatment in Western and Eastern countries. World J Gastroenterol 2015;21:7933-43.

76. Gockel I, Sgourakis G, Lyros O, et al. Risk of lymph node metastasis in submucosal esophageal cancer: a review of surgically resected patients. Expert Rev Gastroenterol Hepatol 2011;5:371-84.

77. Overholt BF, Wang KK, Burdick JS, et al. Five-year efficacy and safety of photodynamic therapy with Photofrin in Barrett's high-grade dysplasia. Gastrointest Endosc 2007;66:460-8.

78. Pech O, Behrens A, May A, et al. Long-term results and risk factor analysis for recurrence after curative endoscopic therapy in 349 patients with high-grade intraepithelial neoplasia and mucosal adenocarcinoma in Barrett's oesophagus. Gut 2008;57:1200-6.

79. Shaheen NJ, Greenwald BD, Peery AF, et al. Safety and efficacy of endoscopic spray cryotherapy for Barrett's esophagus with high-grade dysplasia. Gastrointest Endosc 2010;71:680-5.

80. Shaheen NJ, Sharma P, Overholt BF, et al. Radiofrequency ablation in Barrett's esophagus with dysplasia. N Engl J Med 2009;360:2277-88.

81. Milano RV, Bergman JJ, Pouw RE. Endoscopic treatment of early esophageal adenocarcinoma. Minerva Chir 2018;73:355-65.

82. Lin JL. T1 esophageal cancer, request an endoscopic mucosal resection (EMR) for in-depth review. J Thorac Dis 2013;5:353-6.

83. van Vilsteren FG, Pouw RE, Seewald S, et al. Stepwise 
radical endoscopic resection versus radiofrequency ablation for Barrett's oesophagus with high-grade dysplasia or early cancer: a multicentre randomised trial. Gut 2011;60:765-73.

84. Tao M, Zhou X, Hu M, et al. Endoscopic submucosal dissection versus endoscopic mucosal resection for patients with early gastric cancer: a meta-analysis. BMJ Open 2019;9:e025803.

85. Hoteya S, Matsui A, Iizuka T, et al. Comparison of the clinicopathological characteristics and results of endoscopic submucosal dissection for esophagogastric junction and non-junctional cancers. Digestion 2013;87:29-33.

86. Dubecz A, Kern M, Solymosi N, et al. Predictors of Lymph Node Metastasis in Surgically Resected T1 Esophageal Cancer. Ann Thorac Surg 2015;99:1879-85; discussion 1886.

87. Ahn JY, Jung HY, Choi KD, et al. Endoscopic and oncologic outcomes after endoscopic resection for early gastric cancer: 1370 cases of absolute and extended indications. Gastrointest Endosc 2011;74:485-93.

88. Shah PM, Gerdes H. Endoscopic options for early stage esophageal cancer. J Gastrointest Oncol 2015;6:20-30.

89. Park SR, Lee JS, Kim CG, et al. Endoscopic ultrasound and computed tomography in restaging and predicting prognosis after neoadjuvant chemotherapy in patients with locally advanced gastric cancer. Cancer 2008;112:2368-76.

90. Sun F, Chen T, Han J, et al. Staging accuracy of endoscopic ultrasound for esophageal cancer after neoadjuvant chemotherapy: a meta-analysis and systematic review. Dis Esophagus 2015;28:757-71.

91. Jeurnink SM, van Eijck CH, Steyerberg EW, et al. Stent versus gastrojejunostomy for the palliation of gastric outlet obstruction: a systematic review. BMC Gastroenterol

Cite this article as: Diaz LI, Mony S, Klapman J. Narrative review of the role of gastroenterologist in the diagnosis, treatment and palliation in gastric and gastroesophageal cancer. Ann Transl Med 2020;8(17):1106. doi: 10.21037/atm-20-4143
2007;7:18.

92. Perez-Miranda M, Tyberg A, Poletto D, et al. EUSguided Gastrojejunostomy Versus Laparoscopic Gastrojejunostomy: An International Collaborative Study. J Clin Gastroenterol 2017;51:896-9.

93. Knyrim K, Wagner HJ, Bethge N, et al. A controlled trial of an expansile metal stent for palliation of esophageal obstruction due to inoperable cancer. N Engl J Med 1993;329:1302-7.

94. Hindy P, Hong J, Lam-Tsai Y, et al. A comprehensive review of esophageal stents. Gastroenterol Hepatol (N Y) 2012;8:526-34.

95. Tringali A, Didden P, Repici A, et al. Endoscopic treatment of malignant gastric and duodenal strictures: a prospective, multicenter study. Gastrointest Endosc 2014;79:66-75.

96. Upchurch E, Ragusa M, Cirocchi R. Stent placement versus surgical palliation for adults with malignant gastric outlet obstruction. Cochrane Database Syst Rev 2018;(5):CD012506.

97. Khashab MA, Bukhari M, Baron TH, et al. International multicenter comparative trial of endoscopic ultrasonography-guided gastroenterostomy versus surgical gastrojejunostomy for the treatment of malignant gastric outlet obstruction. Endosc Int Open 2017;5:E275-81.

98. Issaka RB, Shapiro DM, Parikh ND, et al. Palliative venting percutaneous endoscopic gastrostomy tube is safe and effective in patients with malignant obstruction. Surg Endosc 2014;28:1668-73.

99. Kondoh C, Shitara K, Nomura M, et al. Efficacy of palliative radiotherapy for gastric bleeding in patients with unresectable advanced gastric cancer: a retrospective cohort study. BMC Palliat Care 2015;14:37. 